\title{
Non-surgical and surgical management of tissue recession around a dental implant in the anterior maxilla: a case report
}

\author{
Umberto Uccioli $^{1}$, Alberto Fonzar ${ }^{1}$, Stefania Lanzuolo ${ }^{1}$, Silvio Mario Meloni ${ }^{2}$, Aurea \\ Lumbau $^{2}$, and Marco Tallarico ${ }^{2}$ \\ ${ }^{1}$ Private practice \\ ${ }^{2}$ University of Sassari
}

June 29, 2021

\begin{abstract}
The purpose of this case report was to present a combination of two procedures in the treatment of gingival recessions after implant placement in the anterior maxilla. Decision making process and step-by-step execution of the treatments were presented to describe the clinical and surgical management of the reported case.

Non-surgical and surgical management of tissue recession around a dental implant in the anterior maxilla: a case report

Uccioli Umberto, ${ }^{1}$ Fonzar Alberto, ${ }^{2}$ Lanzuolo Stefania, ${ }^{3}$ Meloni Silvio Mario, ${ }^{4}$ Lumbau Aurea Immacolata, ${ }^{5}$ Tallarico $\mathrm{Marco}^{6}$

1) Uccioli Umberto: DDS Private Practice Frosinone

2) Fonzar Alberto: DDS Private Practice Udine

3) Lanzuolo Stefania: DDS Private Practice Rome

4) Meloni Silvio Mario: DDS, PhD, MS Assistant Professor at the Medical Surgical and

Experimental Sciences, University of Sassari, Italy.

5) Lumbau Aurea Immacolata: DDS, PhD, MS Assistant Professor at the Medical Surgical and

Experimental Sciences, University of Sassari, Italy.

6) Tallarico Marco: DDS, MS, Adjunct professor at the Medical Surgical and Experimental

Sciences, University of Sassari, Italy.

Corresponding author: Marco Tallarico

me@studiomarcotallarico.it

$+393280758769$
\end{abstract}

\section{Abstract}

The purpose of this case report was to present a combination of two procedures in the treatment of gingival recessions after implant placement in the anterior maxilla. Decision making process and step-by-step execution of the treatments were presented to describe the clinical and surgical management of the reported case. 


\section{Key Clinical Message}

Implant placement is not without complications. In esthetic area the results could be dramatic. An interdisciplinary approach is often mandatory to resolve such type of complications.

Keywords : esthetics, dental implant, mucosa recession, connective tissue graft, root coverage

\section{Introduction}

Tooth loss causes inevitable remodeling processes of the alveolar bone in the area of the extraction. This changes usually result in bone volume loss, especially against the buccal side and this could lead to functional and esthetic problems. Although the bone resorption may be highly variable, alveolar ridge resorption takes place mainly during the first three months after tooth extraction, resulting in the loss of as much as $50 \%$ of the buccal wall (1-3). Even if bone volume loss is a global problem, it is mostly stressed in the anterior area because of the high esthetic requirements (4-6). Immediate implant placement and loading would seem to be the gold standard in the anterior area, nevertheless, mid-facial mucosa recession could compromise the final esthetic outcomes (7). Moreover, a higher risk of implant failure could be expected when compared with immediate or early loading performed in healed ridges (8-9). In order to overcame these drawbacks, several techniques and materials intent to minimize the alveolar bone resorption, including different procedures to cover the grafted material during the healing phase, have been introduced (1-3-6). Leaving out the differences between various socket preservation techniques, the common point is that the material introduced into the residual socket should act as space maker, avoiding the complete collapse of the alveolar bone. Socket preservation procedures have been introduced to preserve not only the hard tissue but also the soft tissue contour after a tooth extraction, representing an opportunity to avoid more invasive bone augmentation techniques at a later stage (10). In spite of everything, post-extractive implants in the anterior area still remain a challenge due to a possible unacceptable esthetics, and consequently poor patient satisfaction, due to soft tissue recessions, an unfavorable color, and visible crown margins (1-3). The present case describes the management of an esthetic complication occurred after rehabilitation with a dental implant of a central incisor extracted due to a horizontal fracture.

Case presentation

A 10-year-old young man presented with a composed horizontal fractured (ski trauma) of a previously treated maxillary left incisor, involved all the root thickness, and splitting the tooth in two parts. Initial pictures and radiographs were taken for evaluation (Figures 1,2). Endodontic retreatment was performed and the fracture rhyme has been sealed with MTA after its isolation through ultrasonic device. After composite reconstruction two composite veneer crowns were realized on teeth 11 and 22. After a short period in which they have been splinted together, they were divided. At the following follow-up (every 4 months) the site of the trauma showed an increased palatal probing of $5 \mathrm{~mm}$.

After 12 years, as a result of a second trauma (elbow playing football) the tooth fractured completely. Then, bone sounding with periodontal probing revealed buccal probing depth of approximately $6 \mathrm{~mm}$ (Figure 3 ) and pathological mobility. Clinical signs of inflammation were visible particularly at the palatal side (Figuress 4 and 5). Overall clinical and periodontal conditions of the tooth made the extraction unavoidable. Due to the high patient's esthetic and functional demands, the proposed treatment plan included the initial periodontal therapy, a minimally invasive tooth extraction and socket preservation, and Maryland bridge for at least 4 months. Then, computer-guided, template-assisted implant placement with conventional loading. Finally, a cemented-retained, implant-supported single crown on the left incisor and a veneer in the right incisor.

Since patient given the written consent for the proposed treatment and permission to write up the case, all the clinical and surgical procedures started. Patient was prescribed amoxicillin two grams two times per day for 2 days before and 5 days after surgery. The extraction was performed flapless, as atraumatically as possible, using a periotome and atraumatic elevators (PT1 and EPTSMS, Hu-Friedy Italy, Milan, Italy). A carefully curettage of the socket was performed with alveolar curettes, and then washed with saline. After that, the socket (Figure 6) was grafted with deproteinized bovine bone (Bio-Oss, Geistlich Pharma AG, 
Wolhusen, Switzerland), and the wound was sutured with not absorbable surgical suture. Temporary, resinbonded, cast metal framework prostheses, such as Maryland bridges, was used just for esthetic reasons and fixed to the neighbouring teeth without compressing the extraction site. The first clinic check, one week later, showed a perfect healing of the wound.

Four months later, patient underwent a cone beam computed tomography (CBCT) scan (Cranex 3Dx, Soredex, Tuusula, Finland) by using a wax bite to separate dental arches. Then, the patient received intraoral digital impression taken using the 3M True Definition Scanner (3M Italia, Pioltello, Milano). The digital data (STL, Surface Tessellation Language) were imported in a 3D design software (exocad DentalCAD, Exocad GmbH, Darmstadt, Germany) to realize a virtual wax-up according to the functional and esthetic requirements. Then, the STL and DICOM (Digital Imaging and COmmunications in Medicine) data were imported in a 3D software planning program (3Diagnosys ver. 4.2, 3DIEMME srl, Cantù, Italy). Afterwards, prosthetic-driven implant position was planned and a surgical template was ordered (3,6,11-24). Before implant placement, the patient underwent professional oral hygiene, prophylactic antiseptic with $0.2 \%$ chlorhexidine (Curasept, Curaden Healthcare, Saronno, Italy) for one minute, and prophylactic antibiotic therapy (2 $\mathrm{g}$ of amoxicillin or clindamycin $600 \mathrm{mg}$ if allergic to penicillin). Local anesthesia (articaine with adrenaline 1:100000) was administered 20 min before surgery. Immediately before implant placement, the fit of the surgical template was accurately tried in the patient mouth to achieve a stable fit (Fit Checker, GCTokyo, Japan). The surgical templates were stabilized on the residual teeth and fixed with two preplanned anchor pins. The surgical template was temporary removed to elevate a minimally invasive flap without relation incisors. Then, planned implant (Osstem TSIII, Osstem, Seoul, South Korea) were placed at 35 Ncm using dedicate drills (OsstemGuide Kit [Taper], Osstem) in combination with reduction tools, within the surgical templates containing metallic sleeves (Figures 7-9). Finally, the wound was closed with singlestitch sutures using 4.0 resorbable suture material (Vicryl, Ethicon J\&J International, Sint-Stevens-Woluwe, Belgium) and the temporary prosthesis(Maryland bridge) was cemented.

Two weeks later, after suture removal, Clinical examination revealed papillary recession at the the mesial area of the left maxillary lateral incisor (Figure 10). It was classified as Class III based on the Nordland and Tarnow's classification (25) that means mesio-distal

crystal bone loss. Different non surgical and surgical techniques, such as guided bone reconstruction or connective tissue graft, have been widely discussed with the patient to increase the amount of available bone and/or gingival tissue. After all the benefits and limits of these procedures have been evaluated, the patient was scheduled for fixed orthodontic appliance in order to leveling of the isolated infrabone defect and repositioning of the gingival margin, increasing the amount of attached bone and soft tissue. The orthodontic therapy (Fig 11) was carried out after nonsurgical periodontal therapy, which included scaling and root planing. for four months in combination with a coronal odontoplasty to allow the extrusion of the tooth in the arch (26)

After debonding (five months after implant placement), an incision using microsurgial blades and avoiding perpendicular incisions was performed allow more tissue adaptation and a screw-retained temporary restoration with an ideal emergence profile was delivered (Figures 12,13). Temporary restoration was shaped with a concavity in the distal part avoiding any compression. This design was chosen in preparation for connective tissue grafting, also allow for soft tissue creeping.

One month later, local anesthesia was achieved in the facial and palatal regions using articaine with adrenaline 1:100000. Intrasulcular incisions without vertical releasing incisions were made on either side of the papilla to raise a full thickness flap. After achieving sufficient anesthesia in the maxillary tuberosity region, an epithelialized connective tissue was harvested using gengivectomy technique (two parallel split-thickness incisions close to the bone tuberosity on the buccal and palatal aspect). A fibrine sponge was sutured on the site in order to protect the wound during the healing (by second intention). The connective tissue graft (CTG) was de-epithelialized, trimmed and placed over the recipient site (Figure 14) and stabilized with Vicryl 6.0 suture. Flaps were coronally advanced and sutured along with single stitches using a Supramid non resorbable - synthetic - multifilament 5-0 sutures (Figure 15). Nine months after soft tissue maturation 
(Figures 16-18), patient receive three cemented, single crowns made in lithium disilicate. On the implant, a zirconia abutment was delivered (Figure 19). Patient was enrolled in a hygiene maintenance program with visits every 6 months (Figure 20).

\section{Discussion}

The present case describes the management of an esthetic complication occurred after implant rehabilitation of a central incisor extracted due to a horizontal fracture, with lost of the interdental papilla. The treatment of esthetic defects around teeth and implants, such as, marginal tissue recession, deficient ridges or ridge collapse, is one of the most challenging and least predictable problem and hence, it is a real challenge in modern esthetic dentistry. The loss of papilla can lead to esthetic, phonetic (space allows passage for the air or saliva), and functional (lateral food impaction) problems. Reconstruction of lost interdental papilla can be performed by means of surgical and/or non-surgical techniques. Nevertheless, non-surgical approaches, such as, restorative intervention, can only mask the loss of the tissues. In the present case, the clinical approach was a combination of non-surgical (repeated curettage of the papilla during maintenance therapy, soft tissue development using a screw-retained restoration, and orthodontic extrusion) and surgical procedures (deepithelialized CTG harvested from the maxillary tuberosity), in order to restore the interdental papilla after a significant loss of soft tissue between the implant and the lateral incisor (27-29). Orthodontic extrusion techniques have been described in the literature since 1940s as a tool to restore the interdental bone peak with the idea that attached hard and soft tissues follow tooth movement coronally, increasing the height of the alveolar crest (30). Orthodontic extrusion can be achieved with slow forces $(1 \mathrm{~mm} / \mathrm{month})$ to allow periodontal structures to follow the tooth's eruption, or higher forces in cases where elongation of the clinical crown needs to be obtained (fast eruption, $1 \mathrm{~mm} /$ week). These last cases are associated with fibrotomy (31). According to Tarnow et al., the presence of the interproximal dental papilla depends on the distance between the bone crest and the contact point (32). Following this principle, the left lateral incisor was force to erupt along its axis allowing the bone to follow its movement relocating the crestal bone within $5 \mathrm{~mm}$ of the contact point for papilla support and this is particularly useful in that case where we have 1 implant adjacent to a tooth with crestal bone apical to the tooth's cementoenamel junction (33).

According to a recent randomized controlled trial, which compared the use of CTG with guided bone reconstruction using resorbable membrane to re-establish the convexity at the buccal aspect of single implants, both procedures seem to be effective without significant differences (34). Nevertheless all the cases presented with an horizontal defect, without loss of vertical bone around the adjacent teeth. In the present case report, in order to reconstruct the interproximal papilla next to the implant, a CTG harvested from the tuberosity was used. Connective tissue graft is considered the gold standard in treating soft tissue defects. Literature proven that a connective tissue graft harvested from the maxillary tuberosity presented several advantages compared to traditional palatal graft. Within these, the connective tissue graft harvested from the tuberosity is full of connective fibers and poor of glandular components. Moreover, it is represented by its peculiar tendency to a hyperplastic response in time which makes it a better choice to increase soft tissue thickness compared to the same graft harvested from other donor sites. Finally, CTG from the tuberosity seem to be related to lower patient morbidity (35).

The present case report showed a possible strategy to manage the loss of interdental papilla next to a dental implant in esthetic area using a CTG harvesting the graft from maxillary tuberosity later a guided orthodontic tooth extrusion to induce the remodeling of the bone architecture in order to restore the periodontal peak.

Although both the authors and the patient agreed for the most conservative treatment with low morbidity for the patients and high patient's satisfaction, this approach presented some limitations, including the long treatment time, the need for orthodontics, a surgical procedure, and and adjunctive veneer on the lateral incisor that became necessary follow the orthodontic treatment.

\section{Conclusions}

The presented case report described a successful combination of non-surgical and surgical procedures for the management of an esthetic complications occurred after implant placement in the anterior maxilla. 
From this case we learned that it is the need to be cautious when dealing with the anterior area of the mouth. Slow orthodontic extrusion in combination with a CTG harvested from the maxillary tuberosity and a correct management of the prosthetic profiles have proved effective in the present clinical case. An integrated team approach involving clinicians with different expertise, have to be considered the gold standard for the management of esthetic complications.

\section{Author Contribution}

1) Uccioli Umberto: performed the prosthetic procedures

2) Fonzar Alberto: performed some surgical procedures

3) Lanzuolo Stefania: wrote the manuscript with input from all the authors

4) Meloni Silvio Mario: supervisione the entire work and manuscript

5) Lumbau Aurea Immacolata: supervision and looking for funds

6) Tallarico Marco: performed some surgical and prosthetic procedures

\section{Conflict of interest statement}

All the authors declare no conflict of interest

\section{Ethical statement}

This study was approved by the Ethical Committee of the Aldent University 6/2020

\section{References}

1) Canullo L, Caneva M, Tallarico M. Ten-year hard and soft tissue results of a pilot double-blinded randomized controlled trial on immediately loaded post-extractive implants using platform-switching concept. Clin Oral Implants Res. 2017 Oct;28(10):1195-1203.

2) Esposito M, Tallarico M, Trullenque-Eriksson A, Gianserra R. Endodontic retreatment vs dental implants of teeth with an uncertain endodontic prognosis: 1-year results from a randomised controlled trial. Eur J Oral Implantol. 2017 Sep 21;10:293-308.

3) Meloni SM, Tallarico M, Lolli FM, Deledda A, Pisano M, jovanovic SA. Post-extraction socket preservation using epithelial connective tissue graft versus porcine collagen matrix. One-year results of a randomised controlled trial. Eur J Oral Implantol. 2015;8:39-48.

4) Canullo L, Wiel Marin G, Tallarico M, Canciani E, Musto F, Dellavia C. Histological and Histomorphometrical Evaluation of Postextractive Sites Grafted with Mg-Enriched Nano-Hydroxyapatite: A Randomized Controlled Trial Comparing 4 Versus 12 Months of Healing. Clinical Implant

Dentistry and Related Research. 2016 Oct;18:973-83.

5) Pozzi A, Tallarico M, Moy PK. Immediate loading with a novel implant featured by variablethreaded geometry, internal conical connection and platform shifting: Three-year results from a prospective cohort study. Eur J Oral Implantol [Internet]. 2015;8:51-63.

6) Tallarico M, Meloni SM, Canullo L, Caneva M, Polizzi G. Five-Year Results of a Randomized Controlled Trial Comparing Patients Rehabilitated with Immediately Loaded Maxillary Cross-Arch Fixed Dental Prosthesis Supported by Four or Six Implants Placed Using Guided Surgery.

Clin Implant Dent Relat Res. 2016 18:965-972. 
7) Kan JYK, Rungcharassaeng K, Lozada JL, Zimmerman G. Facial gingival tissue stability following immediate placement and provisionalization of maxillary anterior single implants: a 2- to 8-year follow-up. Int J Oral Maxillofac Implants. 2011 Jan;26:179-87.

8) Atieh MA, Payne AGT, Duncan WJ, Cullinan MP. Immediate restoration/loading of immediately placed single implants: is it an effective bimodal approach? Clinical Oral Implants Research [Internet]. 2009 Jul;20:645-59.

9) Atieh MA, Payne AGT, Duncan WJ, de Silva RK, Cullinan MP. Immediate placement or immediate restoration/loading of single implants for molar tooth replacement: a systematic review and meta-analysis. Int J Oral Maxillofac Implants. 2010 Mar;25:401-15.

10) E Jung R, Zembic A, Pjetursson BE, Zwahlen M, S Thoma D. Systematic review of the survival rate and the incidence of biological, technical, and aesthetic complications of single crowns on implants reported in longitudinal studies with a mean follow-up of 5 years. Clinical Oral Implants Research. 2012 Oct 12;23:2-21.

11) Meloni SM, De Riu G, Pisano M, Dell'aversana Orabona G, Piombino P, Salzano G, Quarato D, Riccardi E, Belli E, Ungari C. Computer-assisted implant surgery and immediate loading in edentulous ridges with dental fresh extraction sockets. Two years results of a prospective case series study.

Eur Rev Med Pharmacol Sci. 2013;17:2968-73.

12) Meloni SM, De Riu G, Pisano M, Lolli FM, Deledda A, Campus G, Tullio A. Implant Restoration of Edentulous Jaws with 3D Software Planning, Guided Surgery, Immediate Loading, and CAD-CAM Full Arch Frameworks. Int J Dent. 2013;2013:683423.

13) Meloni SM, De Riu G, Pisano M, Tullio A. Full arch restoration with computer-assisted implant surgery and immediate loading in edentulous ridges with dental fresh extraction sockets. One year results of 10 consecutively treated patients: guided implant surgery and extraction sockets. J Maxillofac Oral Surg. 2013;12:321-5.

14) Meloni SM, Tallarico M, De Riu G, Pisano M, Deledda A, Lolli FM, Massarelli O, Tullio A. Guided implant surgery after free-flap reconstruction: Four-year results from a prospective clinical trial. J Craniomaxillofac Surg 2015;43:1348-55.

15) Meloni SM, Tallarico M, Pisano M, Xhanari E, Canullo L. Immediate Loading of Fixed Complete Denture Prosthesis Supported by 4-8 Implants Placed Using Guided Surgery: A 5-Year Prospective Study on 66 Patients with 356 Implants. Clin Implant Dent Relat Res. 2017;19:195-206.

16) Meloni SM, Jovanovic SA, Pisano M, De Riu G, Baldoni E, Tallarico M. One-stage horizontal guided bone regeneration with autologous bone, anorganic bovine bone and collagen membranes: Follow-up of a prospective study 30 months after loading. Eur J Oral Implantol. 2018;11:89-95

17) Meloni S.M., Spano G., Mattia Ceruso F., Gargari M., Lumbau A., Baldoni E., Massarelli G., 
Pisano M., Tallarico M. Upper jaw implant restoration on six Implants with flapless guided template surgery and immediate loading: 5 years results of prospective case series. Oral and Implantology 2019;12:151-60.

18) Meloni SM, Jovanovic SA, Urban I, Baldoni E, Pisano M, Tallarico M. Horizontal ridge augmentation using GBR with a native collagen membrane and 1:1 ratio of particulate xenograft and autologous bone: A 3-year after final loading prospective clinical study. Clin Implant Dent Relat Res. 2019; 21:669-677.

19) Tallarico M, Meloni SM. Retrospective Analysis on Survival Rate, Template-Related Complications, and Prevalence of Peri-implantitis of 694 Anodized Implants Placed Using ComputerGuided Surgery: Results Between 1 and 10 Years of Follow-Up. Int J Oral Maxillofac Implants. 2017 Sep/Oct;:1162-1171.

20) Tallarico M, Esposito M, Xhanari E, Caneva M, Meloni SM. Computer-guided vs freehand placement of immediately loaded dental implants: 5-year postloading results of a randomised controlled trial. Eur J Oral Implantol. 2018;11:203-213.

21) Tallarico M, Kim YJ, Cocchi F, Martinolli M, Meloni SM. Accuracy of newly developed sleeve-designed templates for insertion of dental implants: A prospective multicenters clinical trial.

Clin Implant Dent Relat Res. 2019 Feb;21:108-113.

22) Tallarico M, Xhanari E, Pisano M, De Riu G, Tullio A, Meloni SM. Single post-extractive ultrawide $7 \mathrm{~mm}$-diameter implants versus implants placed in molar healed sites after socket preservation for molar replacement: 6-month post-loading results from a randomised controlled trial. Eur J Oral Implantol. 2016;9:263-75.

23) Tallarico M, Martinolli M, Kim Y, Cocchi F, Meloni SM, Alushi A, Xhanari E. Accuracy of Computer-Assisted Template-Based Implant Placement Using Two Different Surgical Templates Designed with or without Metallic Sleeves: A Randomized Controlled Trial. Dent J (Basel). 2019 Apr 2;7(2). pii: E41.

24) Tallarico M, Xhanari E, Kim YJ, Cocchi F, Martinolli M, Alushi A, Baldoni EE, Meloni SM. Accuracy of computer-assisted template-based implant placement using conventional impression and scan model or intraoral digital impression: A randomised controlled trial with 1 year of followup. Int J Oral Implantol (New Malden). 2019;12:197-206.

25) Nordland WP, Tarnow DP. A classification system for loss of papillary height. J Periodontol. 1998;69:1124-6.

26) de Molon RS, de Avila D, de Souza JA, Nogueira AV, Cirelli CC, Cirelli JA. Combination of orthodontic movement and periodontal therapy for full root coverage in a Miller class III recession: A case report with 12 years of follow-up. Braz Dent J. 2012;23:758-63.

27) Han TJ, Takei HH. Progress in gingival papilla reconstruction. Periodontol 2000. 1996;11:65-8.

Ingber JS. Forced eruption: Part II. A method of treating nonrestorable teeth: Periodontal and restorative 
considerations. J Periodontol. 1976;47:203-16.

28) Kokich VG. Esthetics: The orthodontic-periodontic restorative connection. Semin Orthod.

1996;2:21-30.

29) Shapiro A. Regeneration of interdental papillae using periodic curettage. Int J Periodontics Restorative Dent. 1985;5:27-33.

30) Oppenheim A: Artificial elongation of teeth. Am J Orthod Oral Surg 26:931, 1940 Buskin R, Castellon P, Hochstedler JL: Orthodontic extrusion and orthodontic extraction in preprosthetic treatment using implant therapy. Pract Periodontics Aesthet Dent 12:213, 2000.

31) Buskin R, Castellon P, Hochstedler JL. Orthodontic extrusion and orthodontic extraction in preprosthetic treatment using implant therapy. Pract Periodontics Aesthet Dent. 2000 Mar;12(2) 213-9; quiz 220.

32) Tarnow DP, Magner AW, Fletcher P. The effect of the distance from the contact point to the crest of bone on the presence or absence of the interproximal dental papilla. J Periodontol. 1992 Dec;63:995-6.

33) Salama H, Salama M: The role of orthodontic extrusive remodeling in the enhancement of soft and hard tissue profiles prior to implant placement: A systematic approach to the management of extraction site defects. Int J Periodontics Restorative Dent 1993;13:312,

34) De Bruyckere T, Eeckhout C, Eghbali A, et al. A randomized controlled study comparing guided bone regeneration with connective tissue graft to re- establish convexity at the buccal aspect of single implants: A one-year CBCT analysis. J Clin Periodontol. 2018;45:1375-1387

35) Lorenzo Tavelli Shayan Barootchi Henry Greenwell Hom-Lay Wang Is a soft tissue graft harvested from the maxillary tuberosity the approach of choice in an isolated site? J Periodontol. 2019;90:821-825.

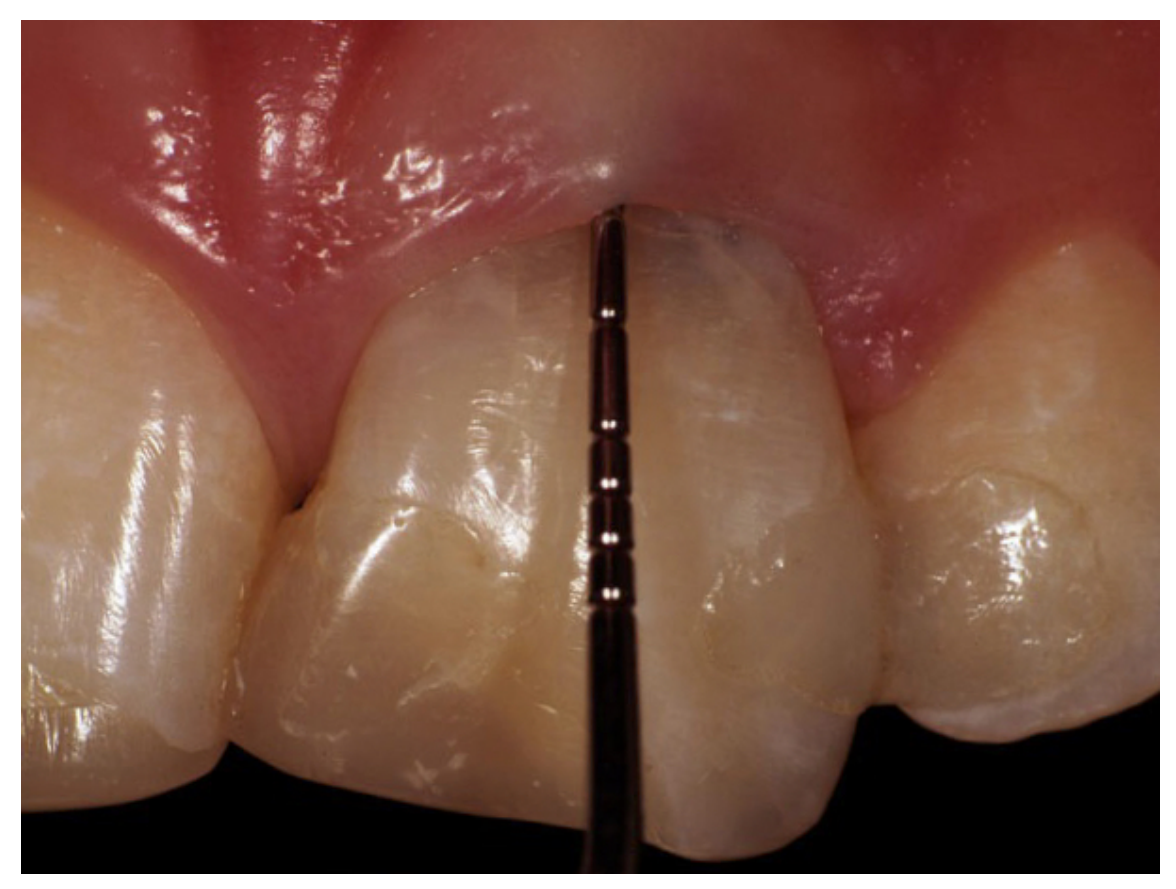

Fig 1 Initial situation at the first trauma, frontal view. 


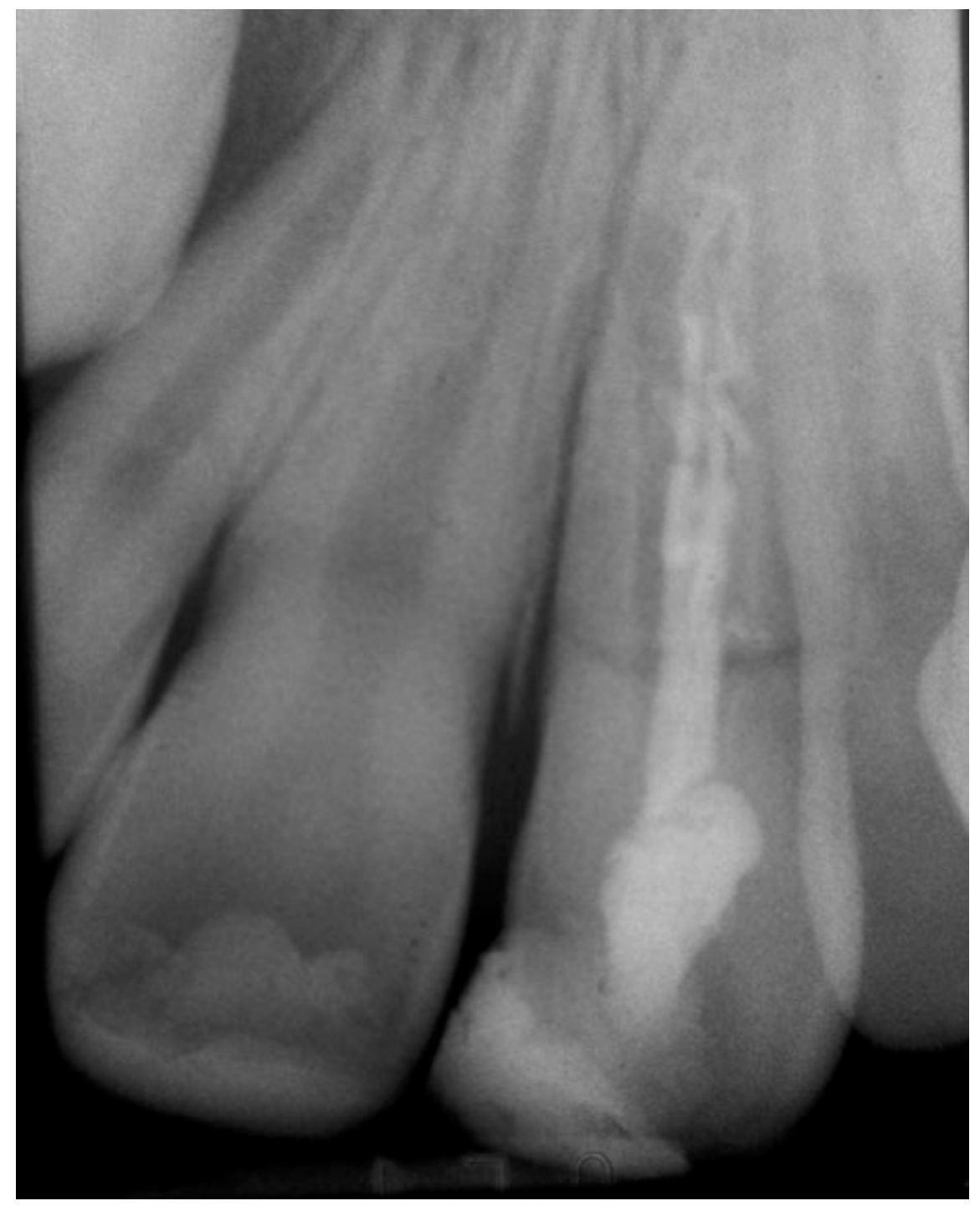

Fig 2 Initial situation at the first trauma, periapical radiograph. 

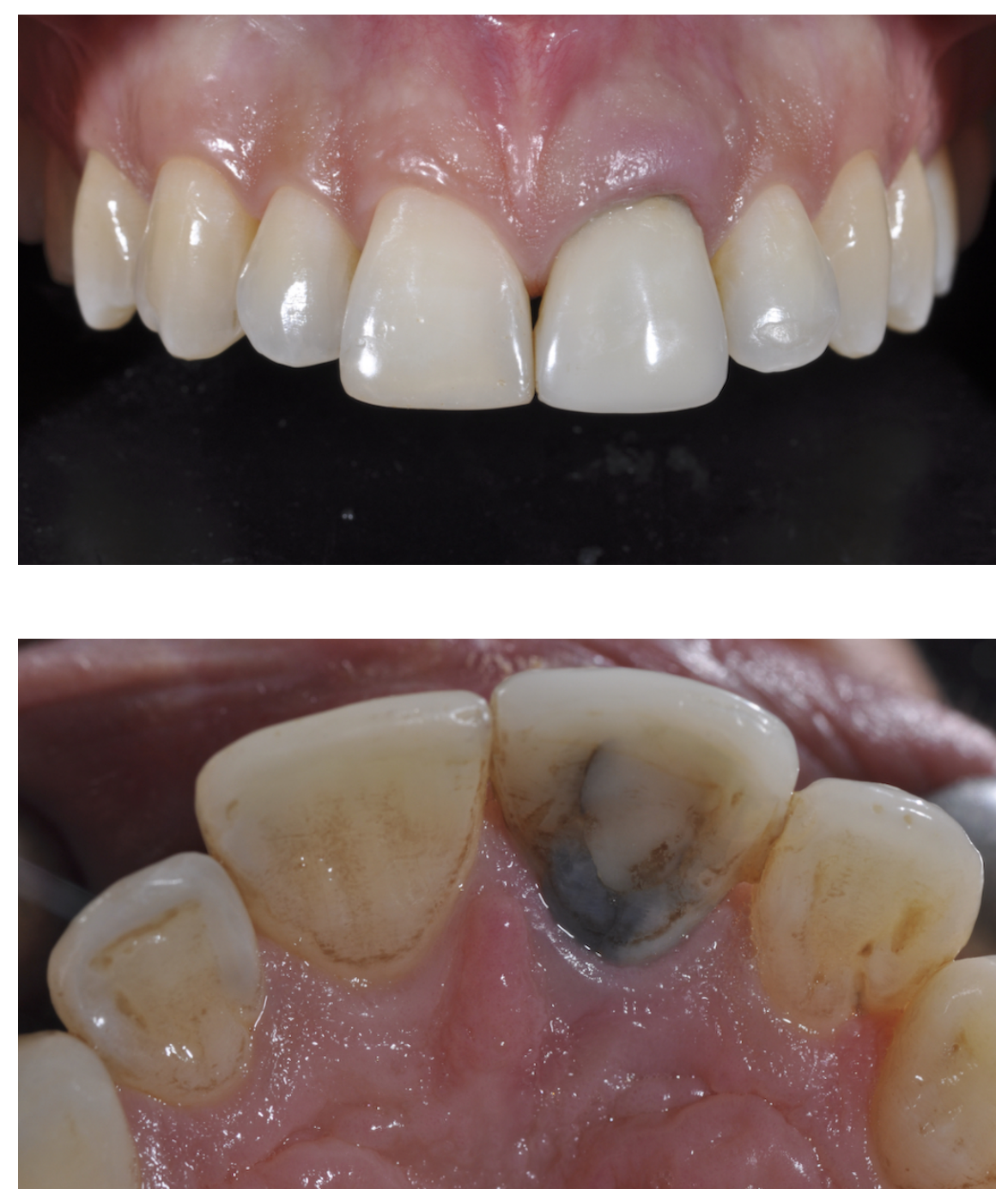

Fig 3 Preclinical intraoral picture, after the second trauma, frontal view.

Fig 4: Preclinical intraoral picture after the second trauma, palatal view. 


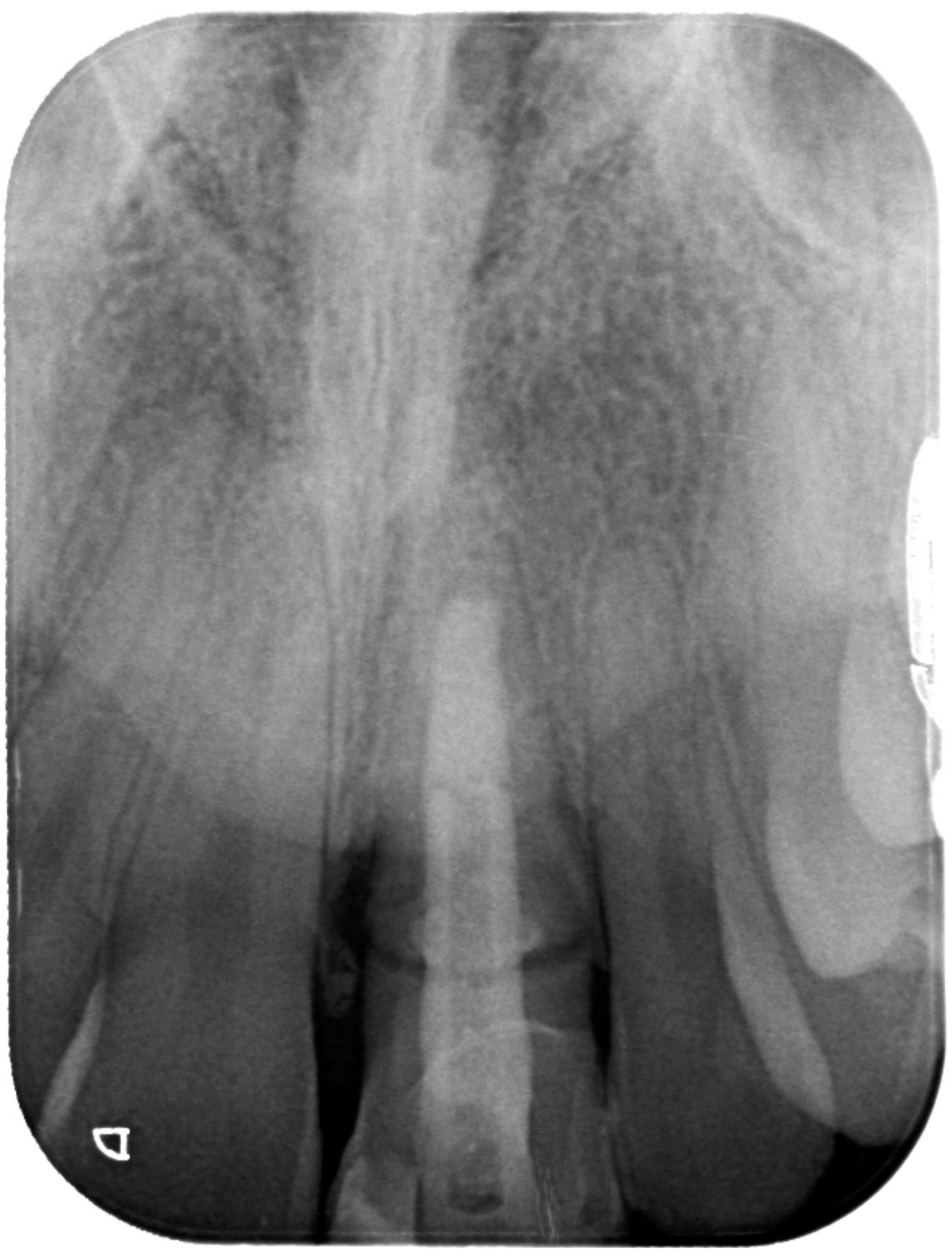

Fig 5: Preclinical radiograph after the second trauma. 


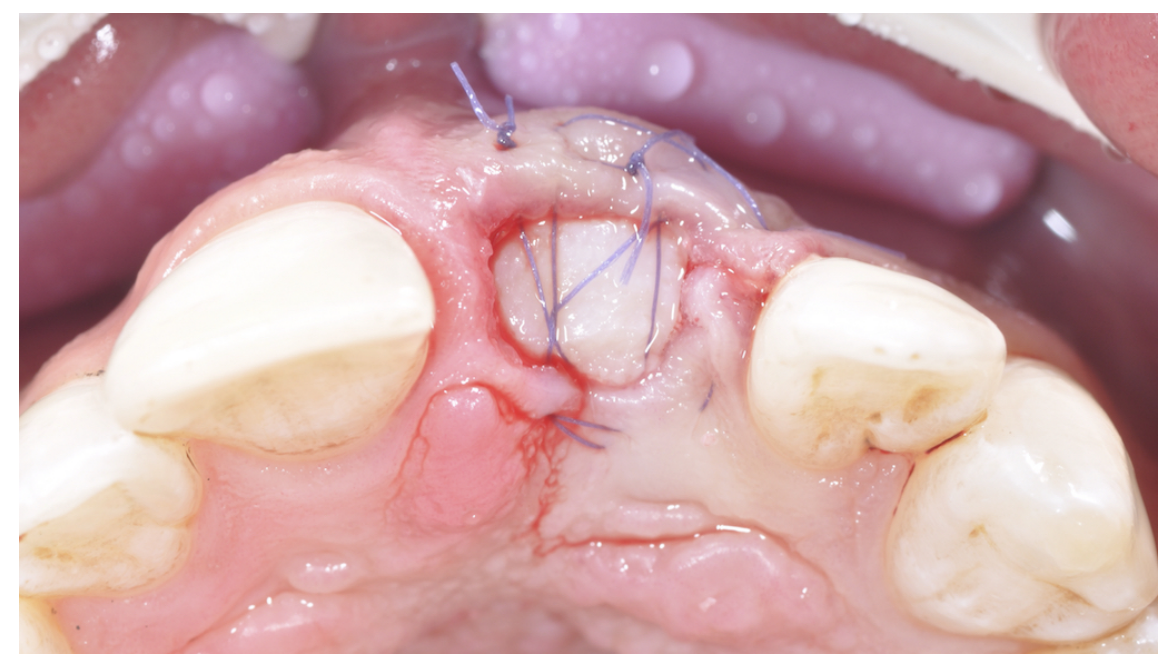

Fig 6: Tooth extraction and socket preservation with deproteinized bovine bone and CTG.

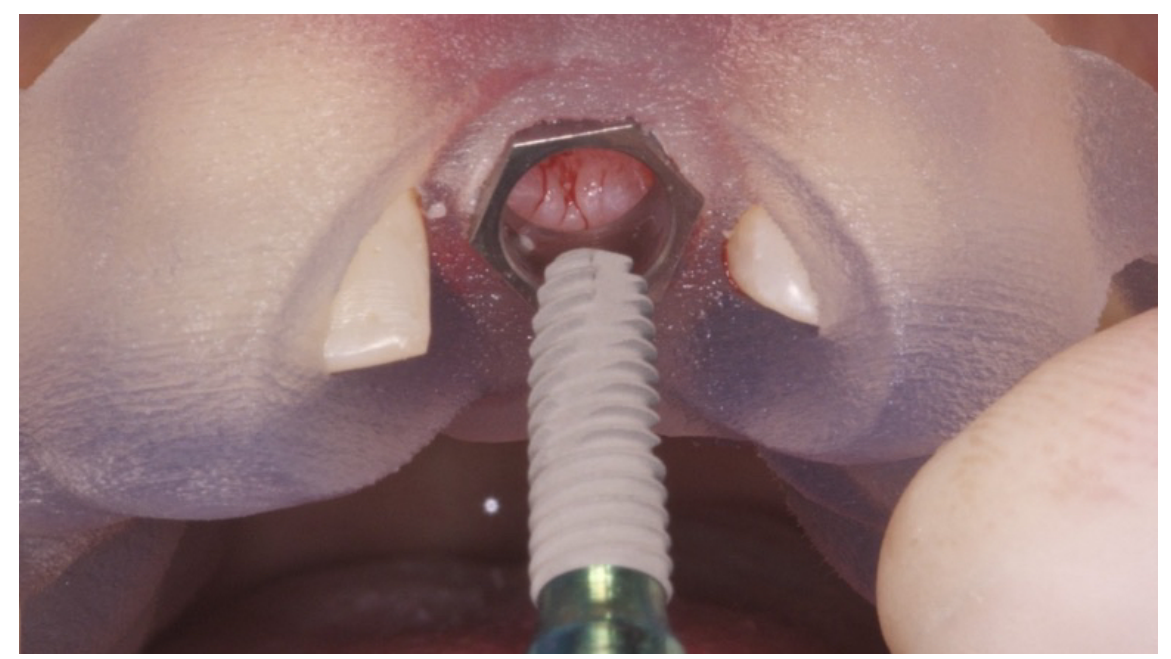

Fig 7: Guided implant placement after four months from the socket preservation. 


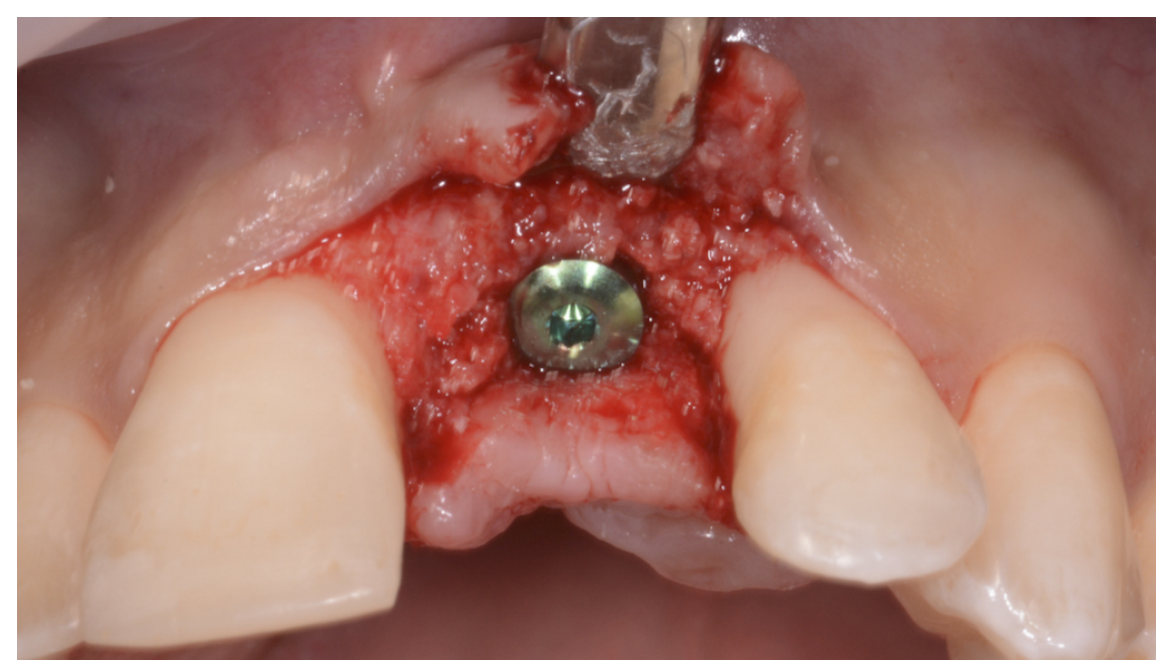

Fig 8: Guided implant placed with minimally invasive flap and submerged healing. 


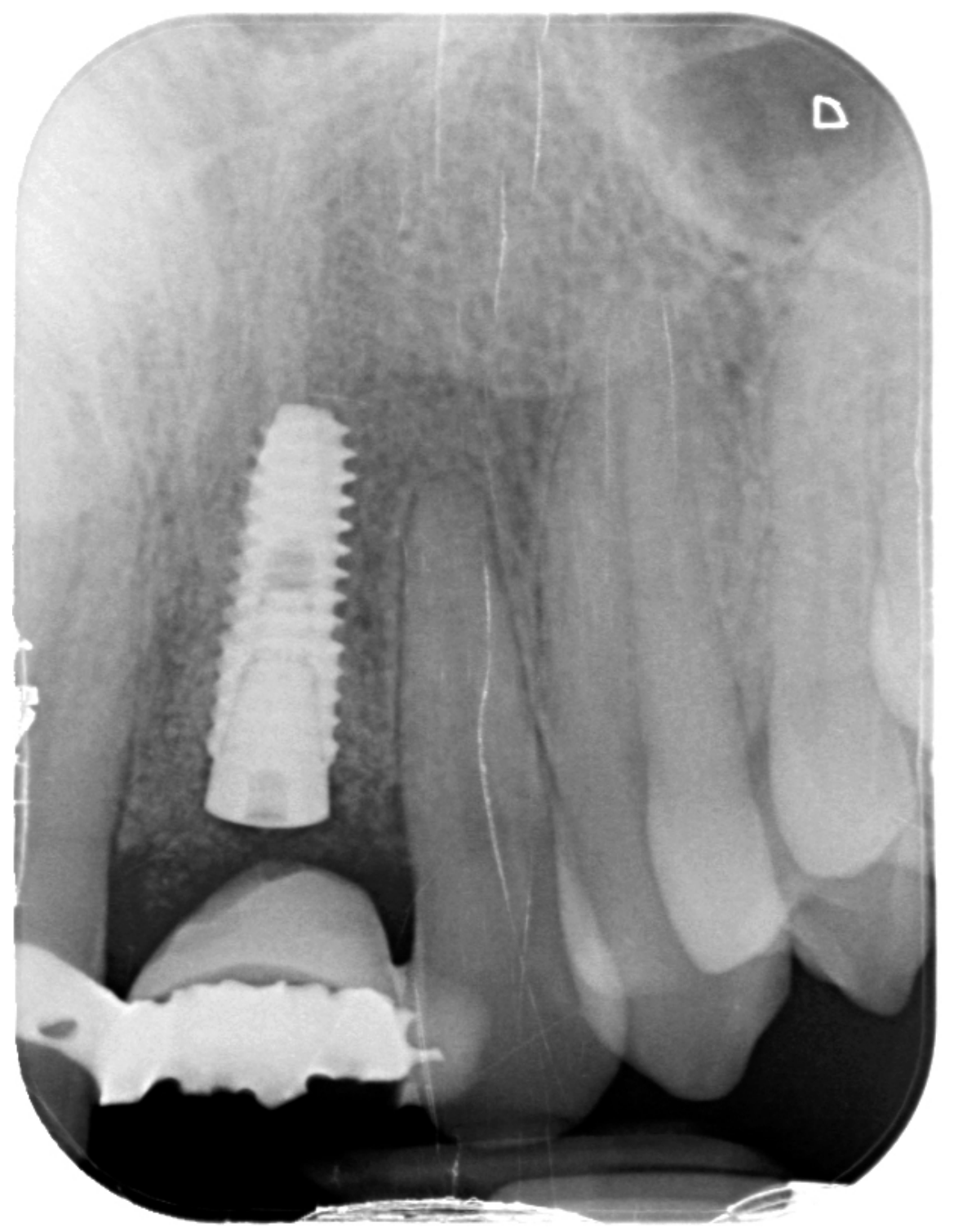

Fig 9: Periapical radiograph after guided implant placement. 


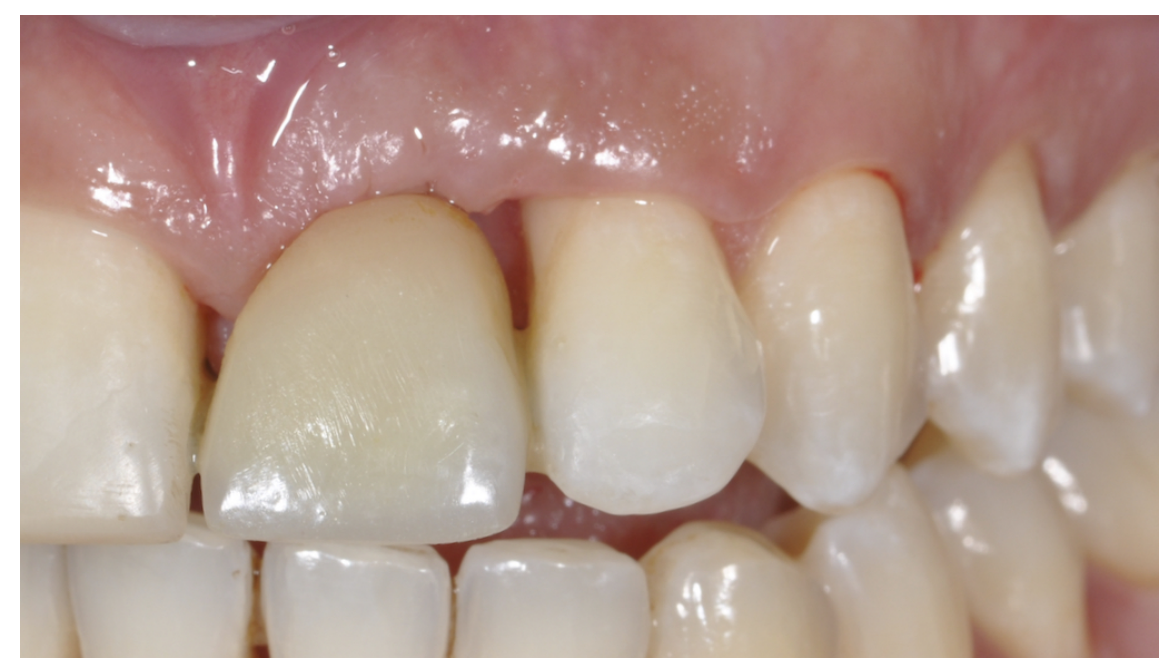

Fig 10: Papilla recession at the the mesial area of the left maxillary lateral incisor two weeks after implant placement.

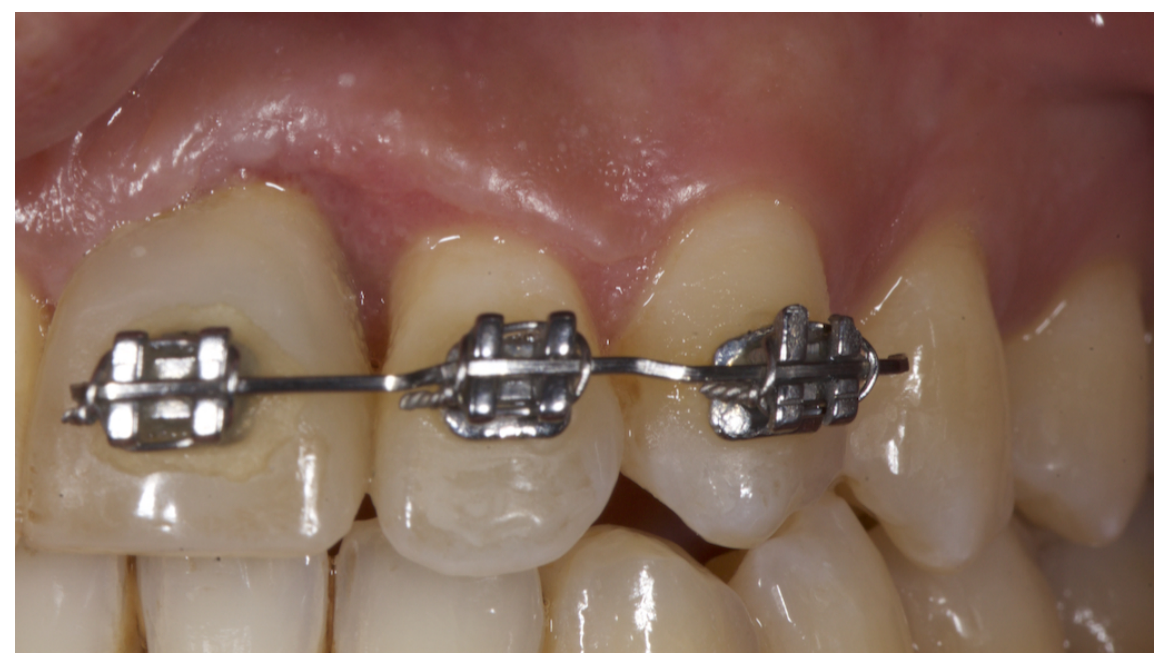

Fig 11: Orthodontic therapy. 


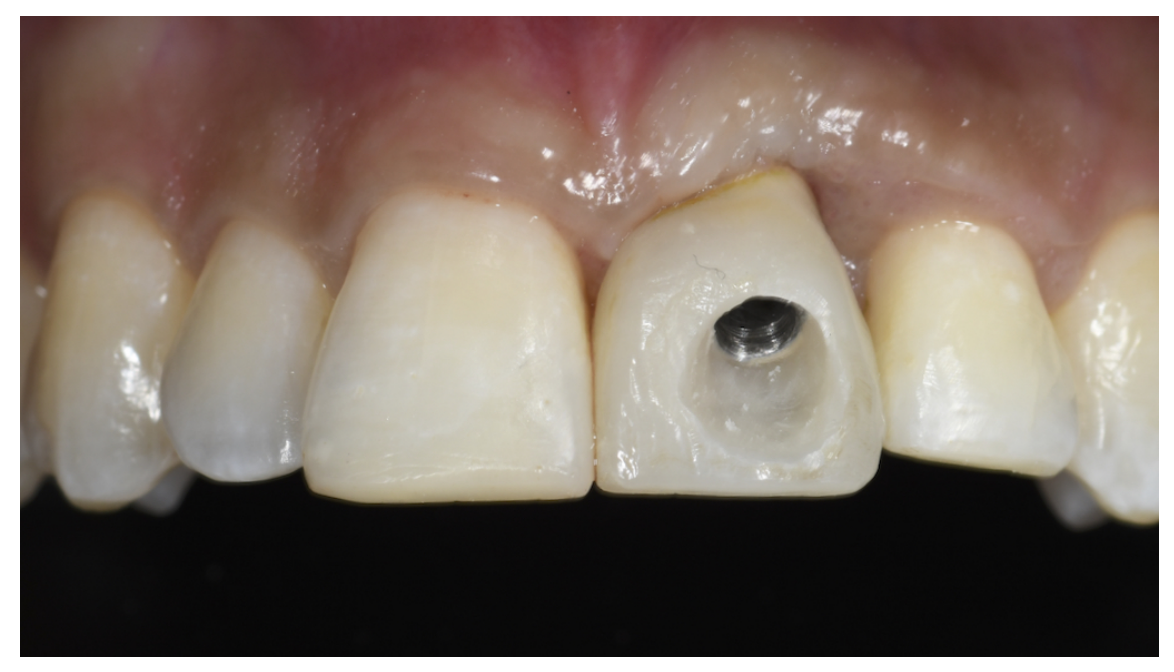

Fig 12: Five months after implant placement, management of soft tissue with screw-retained temporary restoration.

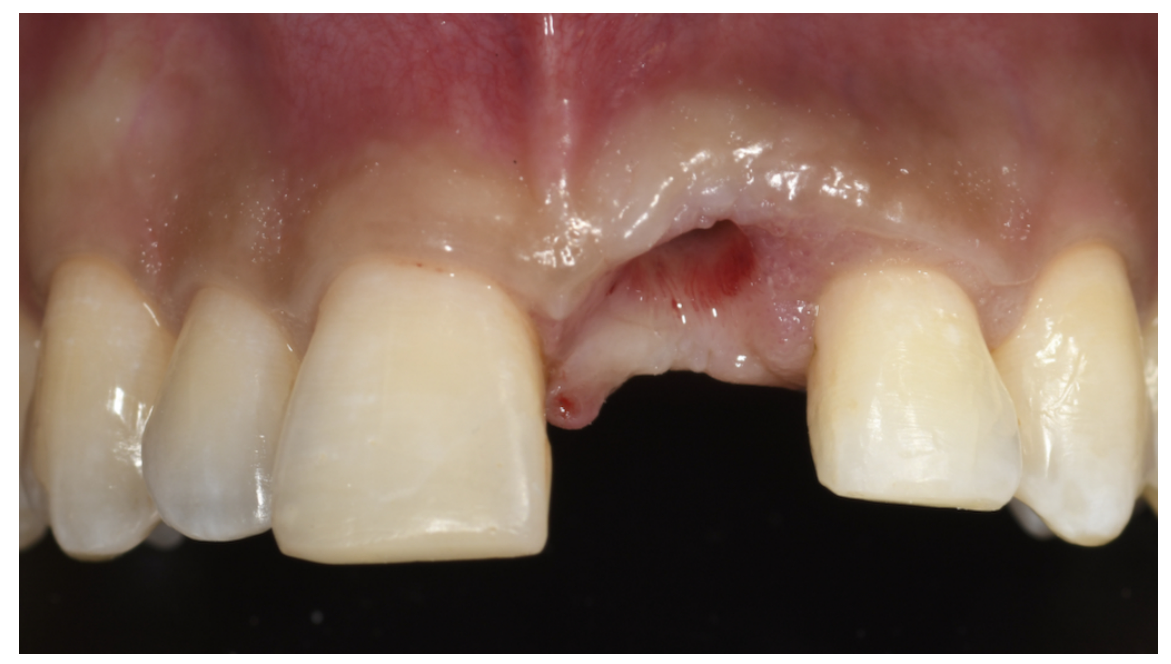

Fig 13: Five months after implant placement, management of soft tissue with screw-retained temporary restoration (without crown). 


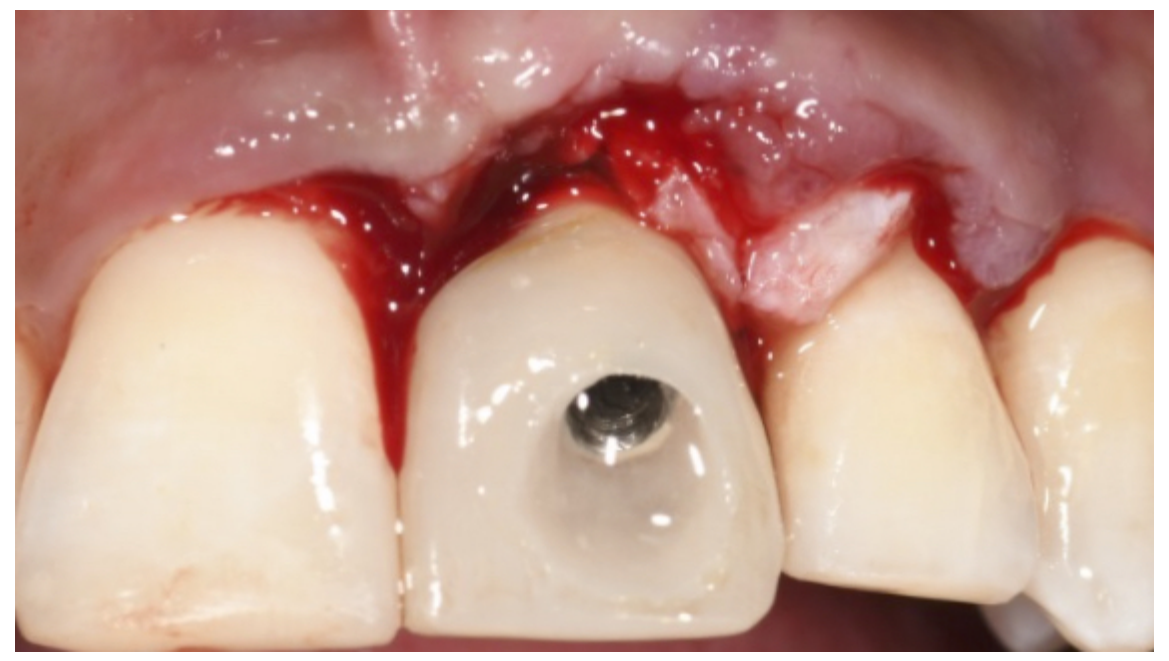

Fig 14: Six months after implant placement, CTG placed over the recipient site.

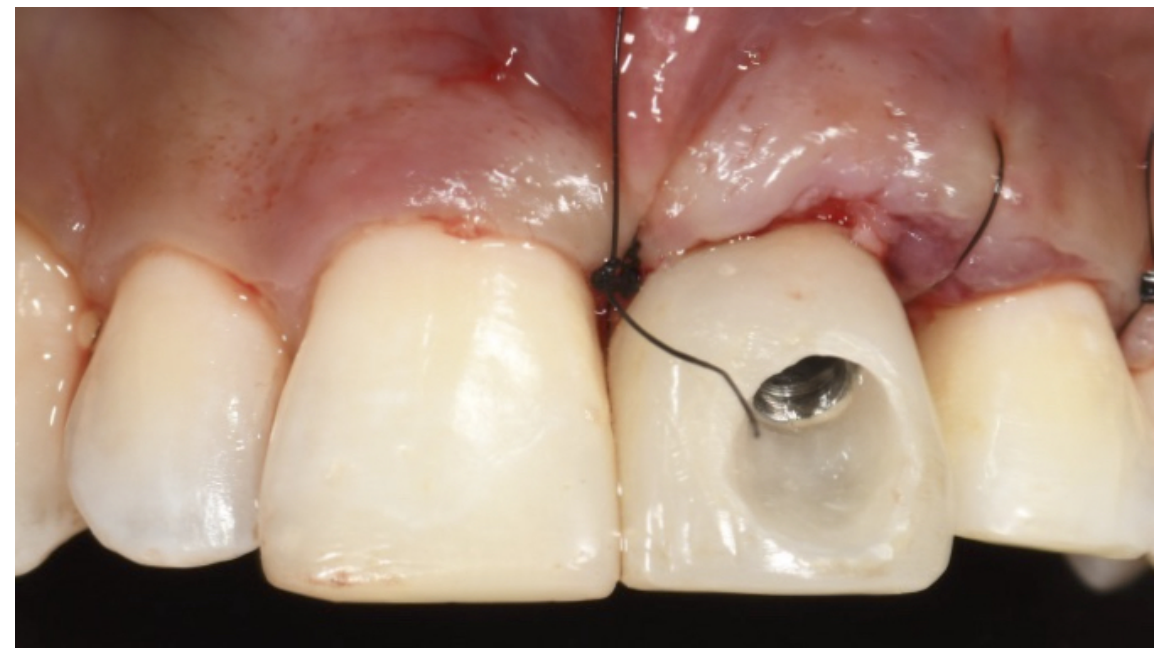

Fig 15: Flaps coronally advanced and sutured along with single stitches using a non resorbable suture. 


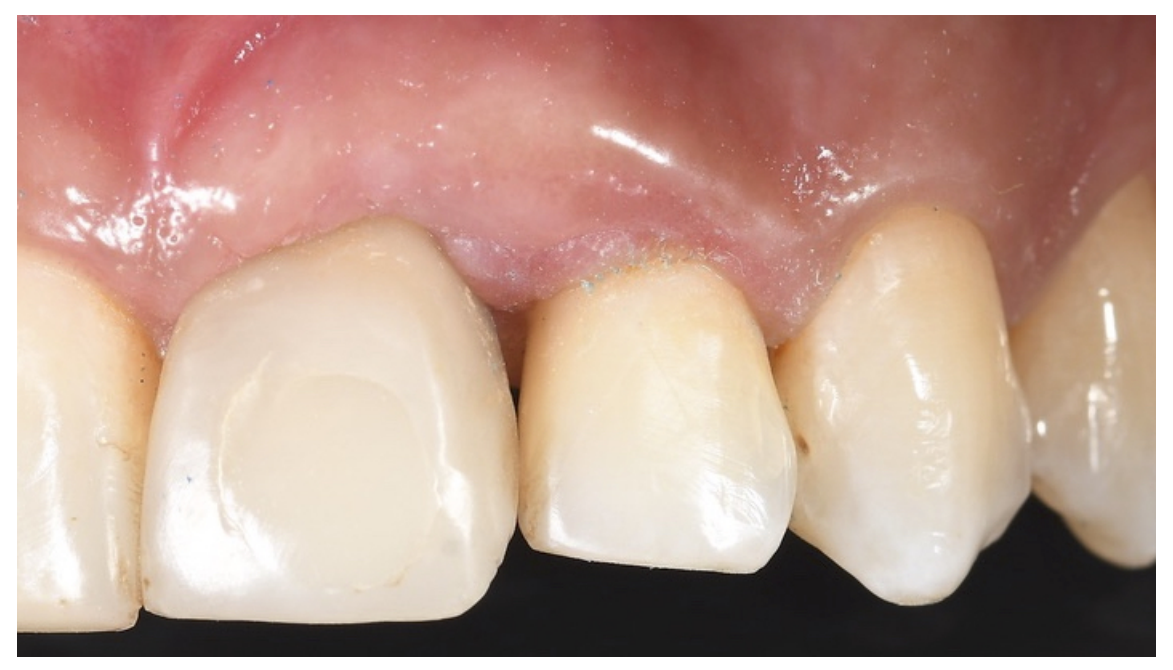

Fig 16: Soft tissue maturation after 10 days from the CTG.

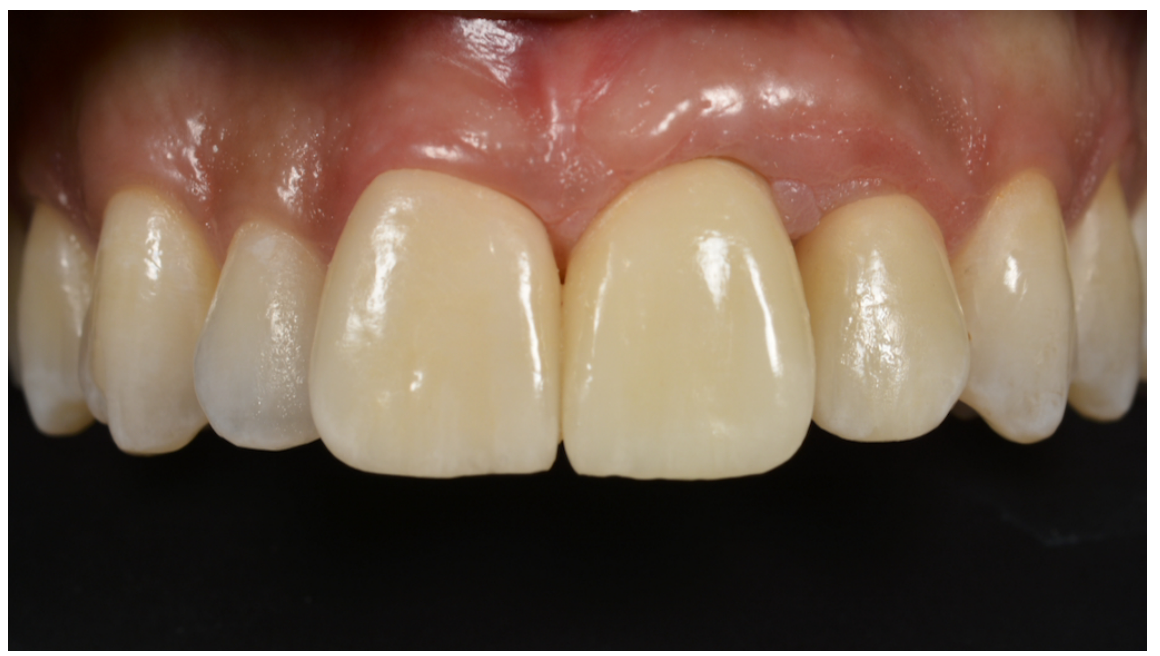

Fig 17: Soft tissue maturation and definitive restorations after 9 months from the CTG. 


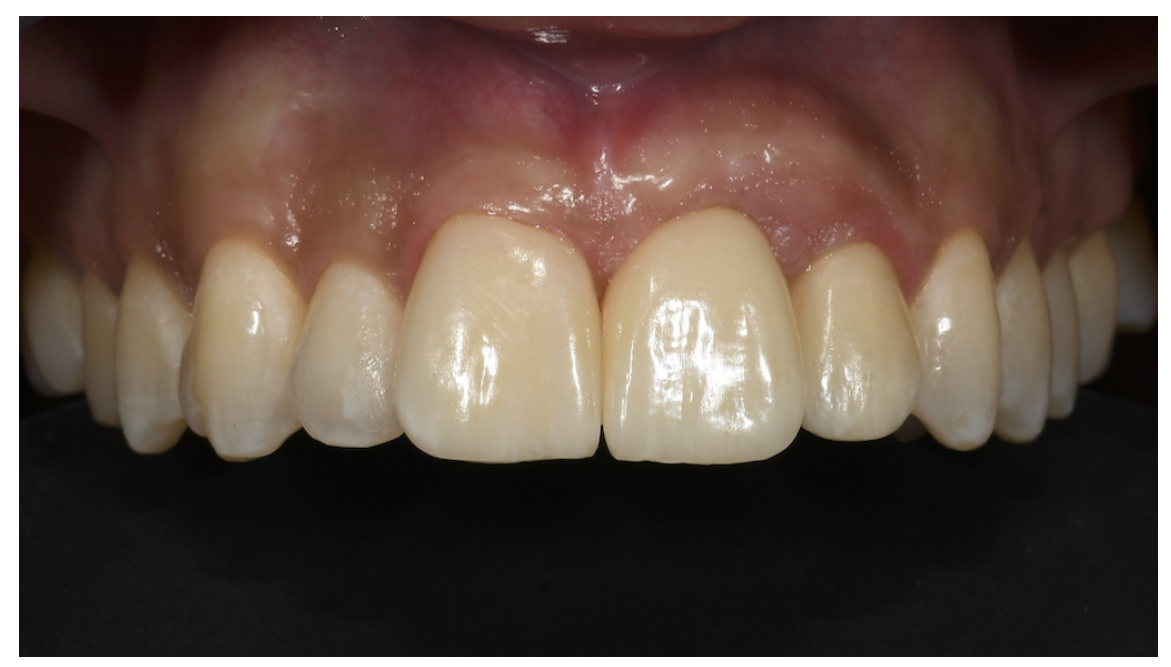

Fig 18: Soft tissue maturation and definitive restorations 1 year after CTG. 


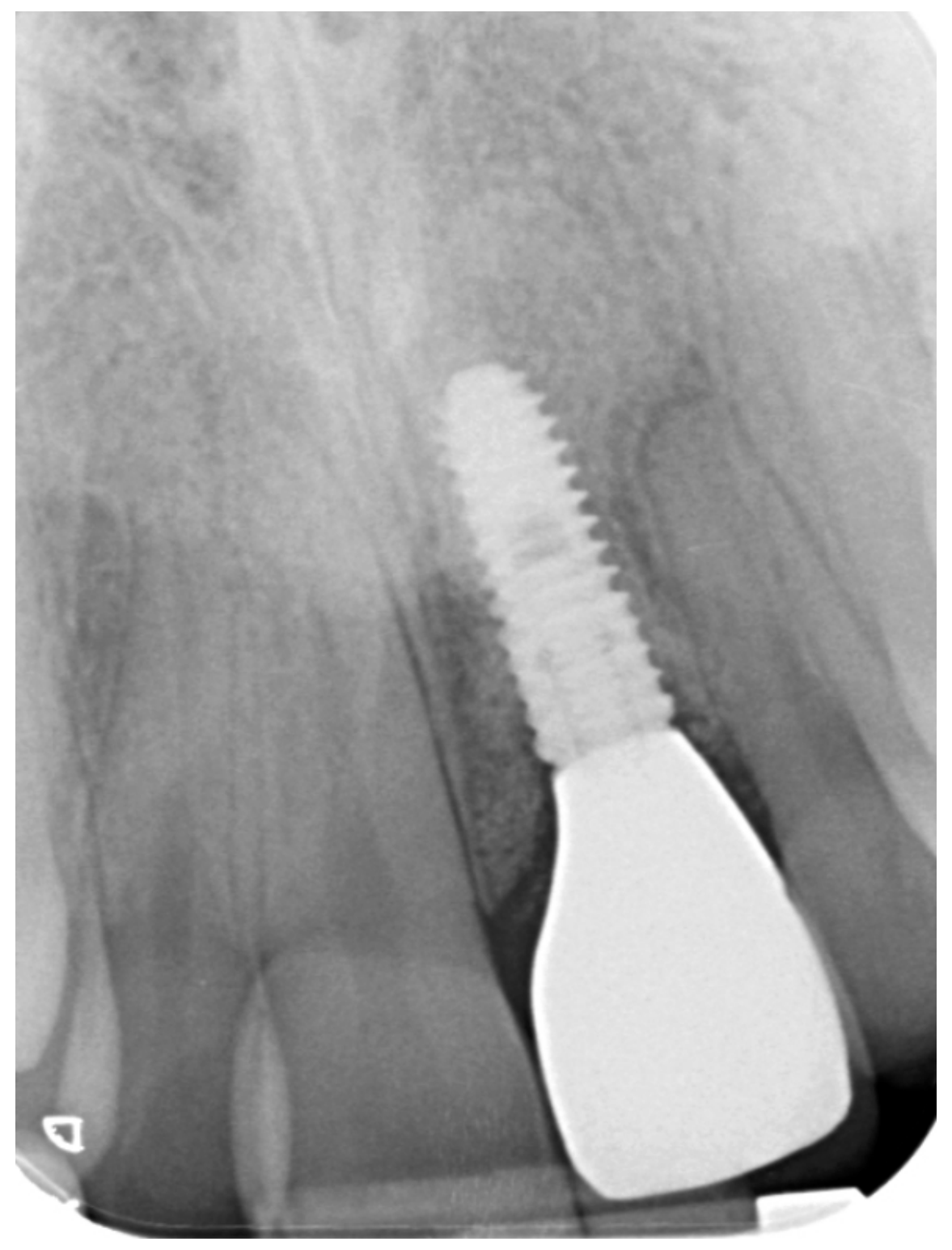

Fig 19: Radiographic evaluation 1 year after CTG. 